\title{
reviews
}

\section{Fascination for discovery}

Dorothy C. Hodgkin

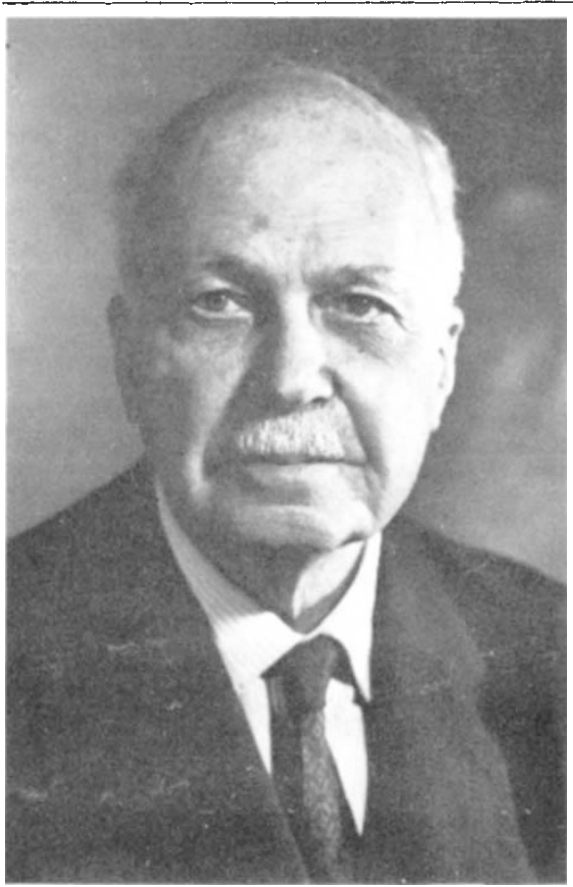

The Development of X-Ray Analysis. $B y$ the late Sir Lawrence Bragg. Edited by D. C. Phillips and H. Lipson. Pp. viii +270 . (Bell: London, 1975.) £6.50.

This book is a joy to read. Over and over again one can almost hear W. L. Bragg talking, as he used to talk when he was with us, always himself fascinated by the problem of solving the next crystal structure, telling us stories meanwhile about the past, mildly debunking, still illuminating.

His point of departure in this book is the discovery of $X$ rays by Röntgen in 1895 and Röntgen's own extensive experiments on their nature. These lead to a general discussion of the evidence for the nature of light and of fundamental particles, and so to the discovery of X-ray diffraction itself, and to the experiments which followed on the structure of crystals and of atoms. In small asides he recaptures moments in the past. "I remember well a fellow student at Jeans' lectures on quantum mechanics, who used to take me aside after the lecture and give me long dissertations on just where Jeans was wrong. This was Bohr-I little knew at the time how great a man was talking to me."

It was one of the important characteristics of W. L. Bragg's own work that he believed in exact and beautiful experiments. So details are given throughout the book of the actual apparatus used and also of the conditions in the different laboratories in which research was organised. He wrote of the Cavendish laboratory of his time "When I achieved the first X-ray reflections I worked the Rumkorff coil too hard in my excitement and burnt out the platinum contact. Lincoln, the mechanic, was very annoyed, as a contact cost ten shillings, and refused to provide me with another one for a month . . I could never have exploited my ideas about X-ray diffraction under such conditions." He moved, in fact, to Leeds, to his father's laboratory, where the facilities were on a very different scale, the consequences of W. H. Bragg's own past experience of setting up a physics laboratory of his own in Adelaide.

To solve the first, quite unknown, crystal structures, W. L. Bragg developed direct and simple arguments, leading to unambiguous answers, and based on a thorough understanding, which he illustrates fully, of optical principles and Fourier analysis. The details of structure determination changed a little as each new family of crystal structures was explored-complex ionic compounds, organic compounds, metallic structures, macromolecules. He took great pleasure in the actual structures found, and this is described in a series of chapters, which end with one on imperfect crystallisations on problems for the future. He also took pleasure in using some of the same simple arguments with which he had solved his first structures to guide the analysis of the most complicated ones, particularly of proteins. His one major omission in the book-any treatment of the statistical approach to phase determination now found in use to be very powerful-probably stems from his liking for unambiguous choices. To examine a series of very probable answers did not appeal to him, even if modern computing and his own contributions to structures solved made choice between them easy.

Not surprisingly in a book published posthumously, a few small errors appear, some of which seem sufficiently interesting historically to mention. The first is perhaps obvious-the photograph interpreted by von Laue on p17 is, as mentioned in the text, zinc

\section{Sorry, for copyright reasons some images on this page may not be available online}

Dorothy Hodgkin is Wolfson Research Professor of the Royal Society at the Chemical Crystallography Laboratory in the University of Oxford, UK.

blende, not copper sulphate (not interpreted till long afterwards). On p107, the map shown is not of a part of vitamin $\mathbf{B}_{12}$ but of the first synthetic corrin derivative - nice indeed that the electron density here was computed to demonstrate that the correct chemical synthesis had been achieved. On p112, the structure shown in Fig. 4a has a negative peak at the hexagon centre, not a positive peak as described in the text. It illustrates a deduction of Dorothy Wrinch's that the centre of the insulin unit cell should be relatively empty to account, in terms of her theory, for the observed Patterson peak heights. And finally, on p181, Bernal's first indications of the sterol structure were obtained in 1932, not 1943.

This is a hook for many different kinds of reader-beginners in X-ray analysis who want to get a feel of the subject, old hands who wish to remember the past, students in other fields who would like to know something of a fascinating region of knowledge and of those who discovered it. We are decply indebted to Professor Phillips and Professor T.ipson for preparing it for publication. 